\title{
Nurses Hand Hygiene Compliance: An Observational Studyin Tamale Teaching Hospital, Ghana
}

\author{
Abdul Rauf Alhassan* \\ Department of Surgery, Tamale Teaching Hospital, P.O. Box TL 16; Tamale-Ghana \\ *Corresponding Author: Abdul Rauf Alhassan, Department of Surgery, Tamale Teaching Hospital, P.O. \\ Box TL 16; Tamale-Ghana
}

\begin{abstract}
Background: The hand of the healthcare worker is acknowledged as the highest route for the spread of exogenous infections mostly through invasive procedures.
\end{abstract}

Aim: To identify hand hygiene compliance among nurses and factors that predicted non-compliance.

Materials and Method: Descriptive cross-sectional study was adopted for this study in the paediatric department of Tamale Teaching Hospital. Data of the study was collected by using the method of observation. Data analysis was done using SPSS version 20. Variables associations were done using chi-square and binary logistic regression analysis.

Results: About 410 indications were observed, the hand hygiene compliance level was 80.2\%. The ward of the participant predicted hand hygiene non-compliance, CEW (AOR = 0.4, 95\%, C.I. 0.162 - 0.890). Also, duty shift predicted hand hygiene non-compliance, afternoon shift (AOR = 3.1, 95\%, C.I. 1.172 - 7.980), night shift $(A O R=8.6,95 \%$, C.I. $3.147-23.359)$. The occupational of participants predicted hand hygiene non-compliance, $R M(A O R=53,95 \%$, C.I. $11.324-252.019)$ as compared to RGN. Finally, the type of hand hygiene indication predicted hand hygiene non-compliance. Comparing hand hygiene before touching patient, hand hygiene after fluid exposure $(A O R=0.05,95 \%$, C.I. $0.005-0.510)$, after patient touch $(A O R=$ 0.06, 95\%, C.I. $0.021-0.199)$ and after touching patient surroundings $(A O R=0.4,95 \%$, C.I. 0.161 0.941).Conclusion: Compliance was good and the ward of the department, duty shift, the occupational category of the nursing category, and type of hand hygiene indicator predicted non-compliance.

Keywords: Hand hygiene, compliance, predictors, Tamale, Teaching, Hospital

\section{INTRODUCTION}

Hospital-acquired infection is one of the current public health problems the world is engulfed with, and the way forward is competent Infection Prevention and Control (IPC) compliance[1].According to Trampuz and Widmer, thousands of people die every day in the world from nosocomial infections acquired through health care procedures through contaminated hands [2]. The influential factors involved in the menace of nosocomial infections in our healthcare backgrounds is poor hand hygiene compliance among healthcare providers[3].

According to Mathur's study, the most competent, easiest, and cost-efficient technique of infection prevention and control is hand hygiene compliance [4].Even though hand hygiene compliance is the way for the prevention of nosocomial infection in our healthcare environment, studies have shown that healthcare workers inclusive nurses do not comply with hand hygiene half the number of times they are supposed to and this has contributed to HAI increase [5].

The hand of the healthcare worker is acknowledged as the highest route for the spread of exogenous infections mostly through invasive procedures [6]. Promoting hand hygiene compliance should be significant for health authorities and all healthcare facilities at all levels, in addition to the individual responsibility of each health provider [5].The World Health Organization has recommended five key moments for hand hygiene in health practice: before contact with a patient, before an aseptic procedure, after contact with a patient, after contact with body fluids, and after touching a patient's surroundings [6]. 
Nakamura and Tompkins's study has revealed that about 5 to $10.0 \%$ of all admitted patients develop nosocomial infections and $70.0 \%$ of the identified pathogens are resistant to one or more of the antimicrobial medicine currently in use [7].Sub-Saharan African countries including Ghana records a high prevalence rate of HAI, ranging from $2.0-49.0 \%$; this is particularly high among critically ill patients admitted to the critical intensive unit where the rate is projected to range from $21.2-35.6 \%$. A survey by Labi et al. in Ghana reported a national prevalence rate of $8.2 \%$ and $8.0 \%$ for Tamale Teaching Hospital [8].A study by Labi, et al. on hand hygiene compliance among healthcare workers in the Northern Region (Kpandai and TataleSanguli), indicated hand hygiene compliance of $49.6 \%$ for pre-intervention and final compliance of $67.9 \%$ after interventions such as such training on IPC.[9] The current emphasized need for hand hygiene practice due to the pandemic of Severe Acute Respiratory Syndrome Coronavirus 2 (SARS-CoV-2) commonly known as Covid-19 necessitated this study to assess hand hygiene compliance among nurses working in the paediatric department of Tamale Teaching Hospital. Since nurses form a major proportion of the health care providers and constitute the "nucleus of the health care system" $[10,11]$. Because they occupy more time with patients than any other healthcare provider, their compliance with hand hygiene guidelines gives the impression to be more vital in preventing nosocomial infection among patients.

\section{RESEARCH DESIGN}

A descriptive cross-sectional study was adopted for this study, using the method of observation for quantitative data.

\subsection{Study Participants and Setting}

The study participants of this study were all nurses working in the paediatric department of Tamale Teaching Hospital. Tamale Teaching Hospital is a major referral teaching hospital in the northern regional capital of Ghana. It serves as the main referral hospital for five northern regions of Ghana, including the neighboring countries to the north of Ghana.

\subsection{Data Collection Tool}

The world health organization checklist for five moments of hand hygiene in the healthcare facility was adopted for this study. The checklist was adopted and modified to suit the objectives of the study. The checklist was divided into demographic characteristics of the participants, such as ward of the observation, day shift of the observation, category, or rank of nurse observed. Moment of hand hygiene opportunity, hand hygiene action (handwashing, hand rub, or missed opportunity).

\subsection{Data Analysis}

Data analysis was done using SPSS version 20. Categorical variables like respondents' sex, and practice level analysis were presented as frequencies and percentages using tables and figures. The hand hygiene compliance level in the department was calculated by dividing the number of present hand hygiene actions (handwashing, hand rub with hand sanitizer, and both) by total hand hygiene indications and multiplying it by 100 . The bivariate analysis was done using Chi-square to determine factors associated with hand hygiene compliance and multivariate analysis for prediction done using binary logistics regression.

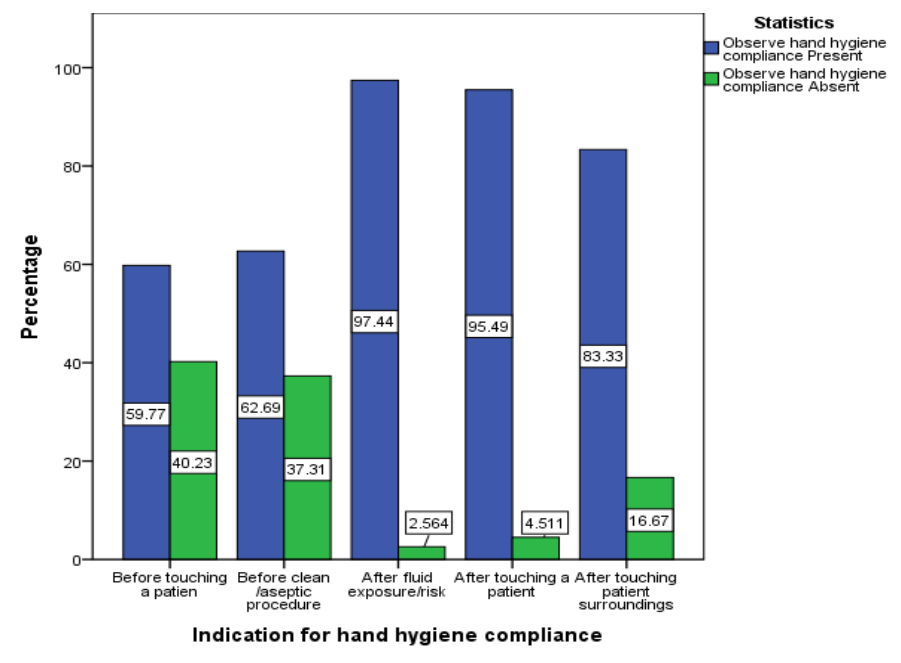

Source: an observational study, 2020

Figure1: Hand hygiene indicators and hand hygiene compliance 


\subsection{Ethical Consideration}

Permission for data collection from the hospitalacquired through the research department of Tamale Teaching Hospital. Since this is an observational study participants were not informed.All sources for information used in this research were duly acknowledged to avoid any form of plagiarism.

\section{Results}

\subsection{Demographic Characteristics of Study Participants}

The study recorded a total of 410 observations. From the observation majority $(51.0 \%)$ of the

Table1: Demographic characteristics of study participants

\begin{tabular}{|c|c|c|c|}
\hline & & Frequency & Percentage \\
\hline \multirow[t]{2}{*}{ Sex } & Male & 201 & 49.0 \\
\hline & Female & 209 & 51.0 \\
\hline \multirow[t]{4}{*}{ Estimated age group } & 18 - 29 years & 107 & 26.1 \\
\hline & $30-39$ years & 283 & 69.0 \\
\hline & $40-49$ years & 10 & 2.4 \\
\hline & $50-59$ years & 10 & 2.4 \\
\hline \multirow[t]{3}{*}{ Category of nurse } & RGN & 349 & 85.1 \\
\hline & $\mathrm{RM}$ & 29 & 7.1 \\
\hline & Enrolled nurse & 32 & 7.8 \\
\hline \multirow[t]{3}{*}{ Ward } & Paediatrics ward & 122 & 29.8 \\
\hline & CEW & 131 & 32.0 \\
\hline & NICU & 157 & 38.3 \\
\hline \multirow[t]{2}{*}{ Day of the work } & Working day & 350 & 85.4 \\
\hline & Weekend & 60 & 14.6 \\
\hline \multirow[t]{3}{*}{ Duty shift } & Morning & 192 & 46.8 \\
\hline & Afternoon & 132 & 32.2 \\
\hline & Night & 86 & 21.0 \\
\hline
\end{tabular}

Source: an observational study, 2020

\subsection{Hand Hygiene Compliance Level}

Out of the 410 indications for hand hygiene compliance, hand hygiene was present or done for 329 indications and not done for 81 indications. Hence the hand hygiene compliance level recorded from observation was $80.2 \%$ and $19.8 \%$ for no compliance. The dominant $(47.3 \%)$ hand hygiene action was hand washing, hand washing was high $(68.4 \%)$ when it came to after touching a patient indication. The second most (17.3\%) hand hygiene action was hand rub with hand sanitizer, hand rub was high $(39.3 \%)$ after touching patient surroundings. Hand hygiene action missed was high $(40.2 \%)$ before touching the patient's surroundings.

From observation, gloves were used in $77.8 \%$ of the indications. The observation indicated that study observations were females and most (69.0\%) of them were within the age bracket of 30 - 39 years. In terms of occupational categorization, most $(85.1 \%)$ of the observations were on registered general nurses. The majority $(38.3 \%)$ were from the neonatal intensive care unit (NICU), 32.0\% from the children's emergency ward (CEW), and 29.8\% from the main pediatric ward. Most of the observations were done during the working day of the week and most (46.8\%) were done during the morning shifts (Table1).

Table2: Chi-square analysis of factors and hand hygiene compliance

\begin{tabular}{|c|c|c|c|c|c|c|c|c|}
\hline & & $\begin{array}{l}\text { Obsert } \\
\text { compli }\end{array}$ & $\begin{array}{l}\text { d } \\
\text { nce }\end{array}$ & & hygiene & & & \\
\hline & & Presen & & & & $X^{2}$ & df & P-value \\
\hline Sex & Male & 157 & $78.1 \%$ & 44 & $21.9 \%$ & 1.133 & 1 & .287 \\
\hline
\end{tabular}


Nurses Hand Hygiene Compliance: An Observational Studyin Tamale Teaching Hospital, Ghana

\begin{tabular}{|c|c|c|c|c|c|c|c|c|c|}
\hline & Female & 172 & $82.3 \%$ & 37 & $17.7 \%$ & & & \multirow{2}{*}{\multicolumn{2}{|c|}{060}} \\
\hline \multirow{2}{*}{$\begin{array}{l}\text { Estimated age } \\
\text { group }\end{array}$} & $<30$ years & 86 & $80.4 \%$ & 21 & $19.6 \%$ & 0.02 & 1 & & \\
\hline & $\geq 30$ years & 224 & $79.2 \%$ & 59 & $20.8 \%$ & & & \\
\hline \multirow{3}{*}{$\begin{array}{l}\text { Category of } \\
\text { nurse }\end{array}$} & RGN & 290 & $83.1 \%$ & 59 & $16.9 \%$ & 49.769 & 2 & \multicolumn{2}{|c|}{.000} \\
\hline & $\mathrm{RM}$ & 9 & $31.0 \%$ & 20 & $69.0 \%$ & & & & \\
\hline & Enroll nurse & 30 & $93.8 \%$ & 2 & $6.2 \%$ & & & & \\
\hline \multirow[t]{3}{*}{ Ward } & Paediatrics & 85 & $69.7 \%$ & 37 & $30.3 \%$ & \multicolumn{2}{|c|}{12.244} & 2 & .002 \\
\hline & CEW & 111 & $84.7 \%$ & 20 & $15.3 \%$ & & & & \\
\hline & NICU & 133 & $84.7 \%$ & 24 & $15.3 \%$ & & & & \\
\hline \multirow[t]{2}{*}{ Day of the work } & Working day & 273 & $78.0 \%$ & 77 & $22.0 \%$ & \multicolumn{2}{|c|}{7.596} & 1 & .006 \\
\hline & Weekend & 56 & $93.3 \%$ & 4 & $6.7 \%$ & & & & \\
\hline \multirow[t]{3}{*}{ Duty shift } & Morning & 181 & $94.3 \%$ & 11 & $5.7 \%$ & \multicolumn{2}{|l|}{57.882} & 2 & .000 \\
\hline & Afternoon & 100 & $75.8 \%$ & 32 & $24.2 \%$ & & & & \\
\hline & Night & 48 & $55.8 \%$ & 38 & $44.2 \%$ & & & & \\
\hline \multirow{2}{*}{$\begin{array}{l}\text { Hand hygiene } \\
\text { materials } \\
\text { available }\end{array}$} & Water and Soap & 78 & $68.4 \%$ & 36 & $31.6 \%$ & \multicolumn{2}{|l|}{13.923} & 1 & .000 \\
\hline & $\begin{array}{ll}\text { Water and } & \text { soap } \\
\text { plus } & \text { hand } \\
\text { sanitizer } & \end{array}$ & 251 & $84.8 \%$ & 45 & $15.2 \%$ & & & & \\
\hline
\end{tabular}

Source: an observational study, 2020

\subsection{Indicators for Hand Hygiene and Hand Hygiene Compliance}

Chi-square analysis indicated a significant relation between WHO five moments hand hygiene indicators and actual hand hygiene compliance, $X^{2}(4,410)=63.307, \mathrm{P} \leq 0.001$. Proportionally after body fluid exposure hand hygiene indicator recorded the highest (97.4\%) hand hygiene compliance, next was after touching a patient $(95.5 \%)$, then after touching the patient environment (83.3\%), after that, was before the clean or aseptic procedure and finally and least $(59.8 \%)$ complied indicator was before touching a patient (Figure1).

\subsection{Multiple Logistics Regression of Factors Associated with Hand Hygiene Non- Compliance}

The ward of the participant predicted hand hygiene non-compliance, those in CEW were about $60 \%$ less likely to non-comply with hand hygiene as compared to those in the paediatric ward $(\mathrm{AOR}=0.4,95 \%$, C.I. $0.162-0.890)$. Also, the shift of the day predicted hand hygiene non-compliance, those on the afternoon shift were three times likely to non-comply with hand hygiene as compared to those on the morning shift $(\mathrm{AOR}=3.1,95 \%$, C.I. $1.172-7.980)$. And those on the night shift were almost nine times likely to non-comply with hand hygiene as compared to those on the morning shift (AOR = 8.6, 95\%, C.I. 3.147 - 23.359). The occupational of participant predicted hand hygiene non-compliance, registered midwives were about 53 times likely to non-comply with hand hygiene as compared to registered general nurses (AOR $=53,95 \%$, C.I. $11.324-252.019$ ). Finally, the type of hand hygiene indication predicted hand hygiene non-compliance. Comparing hand hygiene before touching patient, non-compliance with the other hand hygiene indicators were less likely, hand hygiene after fluid exposure (AOR $=0.05,95 \%$, C.I. $0.005-0.510)$, after patient touch (AOR $=$ 0.06 , 95\%, C.I. $0.021-0.199)$ and after touching patient surroundings $(\mathrm{AOR}=0.4,95 \%$, C.I. $0.161-0.941)$ (Table 3).

Table3: Binary logistic regression for predictors of hand hygienenon-compliance

\begin{tabular}{|c|c|c|c|c|c|c|}
\hline & \multirow[b]{2}{*}{ B } & \multirow[b]{2}{*}{ Wald } & \multirow[b]{2}{*}{ Sig. } & \multirow[b]{2}{*}{ AOR } & \multicolumn{2}{|c|}{$\begin{array}{l}\text { H-L GOF test } \\
\text { X2 }(8)=14.297, P=0.074 \\
95 \% \text { C.I. for } A O R\end{array}$} \\
\hline & & & & & Lower & Upper \\
\hline Paediatrics ward & & & Ref & & & \\
\hline CEW & -.969 & 4.968 & .026 & .379 & .162 & .890 \\
\hline NICU & -1.134 & 2.871 & .090 & .322 & .087 & 1.195 \\
\hline $\begin{array}{l}\text { Day of the Work (weekend / } \\
\text { Working day) }\end{array}$ & -.572 & .868 & .352 & .564 & .169 & 1.881 \\
\hline Morning & & & Ref & & & \\
\hline Afternoon & 1.118 & 5.219 & .022 & 3.058 & 1.172 & 7.980 \\
\hline Night & 2.149 & 17.658 & .000 & 8.574 & 3.147 & 23.359 \\
\hline RGN & & & Ref & & & \\
\hline
\end{tabular}




\begin{tabular}{|c|c|c|c|c|c|c|}
\hline $\mathrm{RM}$ & 3.978 & 25.264 & .000 & 53.423 & 11.324 & 252.019 \\
\hline EN & -.384 & .203 & .653 & .681 & .128 & 3.622 \\
\hline Before touching a patient & & & Ref & & & \\
\hline Before clean /aseptic procedure & -.364 & .641 & .423 & .695 & .285 & 1.694 \\
\hline After fluid exposure/risk & -3.014 & 6.365 & .012 & .049 & .005 & .510 \\
\hline After touching a patient & -2.750 & 22.583 & .000 & .064 & .021 & .199 \\
\hline $\begin{array}{l}\text { After touching the patient } \\
\text { surroundings }\end{array}$ & -.944 & 4.391 & .036 & .389 & .161 & .941 \\
\hline $\begin{array}{l}\text { Hand hygiene material } \\
\text { availability }\end{array}$ & -.530 & 1.917 & .166 & .589 & .278 & 1.246 \\
\hline
\end{tabular}

Source: an observational study, 2020

The logistic regression model appropriately explained the outcome variable (hand hygiene compliance) since the Hosmer-Lemeshow goodness-of-fit test $p$-value was more than 0.05 , $\left(X^{2}(8)=14.297, p=0.074\right)($ Table 3$)$, hence the model fits the study data (Table 3 ).

\section{DISCUSSION}

The study recorded a total of 410 observations, about $32.4 \%$ of them were on after touching a patient, then $21.2 \%$ were on before touching a patient, and least was on after body fluid exposure. The majority (47.3\%) of actions taken for hand hygiene compliance was hand washing, then $17.3 \%$ for hand rub with hand sanitizer. About $15.6 \%$ of actions for hand hygiene were both handwashing and hand rub with hand sanitizer. However, there was a missed action of $19.8 \%$ for hand hygiene opportunities. Also in a similar study, the most $(63.6 \%)$ preferred method of hand hygiene was washing with water and soap [12]. Healthcare workers ought to embrace either one procedure for hand hygiene, thus alcohol hand-rub or handwashing with antimicrobial or non-antimicrobial soap, but hand washing is recommended if the hands are dirty. The usage of both procedures concurrently is not endorsed, as it doubles both cost and time.

From observation, gloves were used in $77.8 \%$ of the indications. The observation indicated that hand hygiene was only practiced $8.8 \%$ before glove use and $96.9 \%$ after glove use. Appropriate hand hygiene is essential before wearing gloves, as trapped moisture under gloves can be a source of skin irritation and upsurge the harboring of bacteria. A recent study in the surgical department of TTH by Alhassan et al. on hand hygiene and facemask compliance among healthcare providers reported a below-average number of participants complying with hand hygiene [17]. However, in this current hand hygiene compliance level recorded from observation was $80.2 \%$ and $19.8 \%$ for non-compliance. In Ghana, a study in
Cape coast Teaching Hospital indicated a low hand hygiene compliance thus, $27.3 \%$ [13]. Also, in Ethiopia, an observational study on hand hygiene compliance among healthcare workers revealed overall compliance of $22.0 \%$ among the health care workers [14]. This study finding is still very high when compared to another observational study in Istanbul, Turkey using a sum of 704 hand hygiene opportunities observed from the neonatal and pediatric intensive care units in Marmara University, Pendik Training and Research Hospital, from June 2013 to July 2013, rather a low hand hygiene compliance of $37.0 \%$ (261/704) among the healthcare workers [12].

The current study revealed a statistically significant relationship between the professional nursing category and hand hygiene compliance. Registered midwives predicted hand hygiene compliance for about 53 times likely as compared to registered general nurses, this is in line with another study where compliance varied by occupation [12]. However, in another study, there was no difference in hand hygiene compliance among professional groups [15].

This study revealed a significant relationship between wards of the department, those in CEW were about $60 \%$ less likely to non-comply with hand hygiene as compared to those in the paediatric ward. NICU and CEW are perceived to be busy wards of the department, so would have been expected that the higher workload will result in low hand hygiene compliance as compared to the paediatric ward. Since in a similar study in Ghana workload was a factor related to poor hand hygiene compliance [13].

Day of the week was significantly related to hand hygiene compliance, compliance was high $(93.3 \%)$ during weekends as compared to $8.0 \%$ for working days. Even though this did not predict hand hygiene compliance at the multivariate analysis, this is expected as working days are usually the busy days hence the likelihood of non-compliance. The shift of 
the day was also related to compliance, those on the morning shift were more likely to comply with hand hygiene as compared to those on the night. Hand hygiene non-compliance was highly predicted by the night shift as those on the night were about nine times likely to non-comply as compare to those on the morning shift. Also, those on the afternoon shift were about three times likely to non-comply as compared to those in the morning. More compliance for the morning shift can be related to the fact that day time duties are usually associated with the availability of working materials. Meanwhile, in another study, there was no difference in hand hygiene compliance among different shifts of the day [15].

Finally, the study revealed a significant relation between WHO five moments hand hygiene indicators and actual hand hygiene compliance. Comparing hand hygiene before touching a patient, non-compliance with the other hand hygiene indicators were less likely. Hand hygiene non-compliancewas only likely 0.05 times after fluid exposure. Hand hygiene noncompliancewas likely only 0.06 times after patient touch. And after touching patient surroundings non-compliance was only likely for about $40 \%$. In Ethiopia, an observational study on hand hygiene compliance among healthcare workers revealed hand hygiene compliance was higher after body fluid exposure $75.8 \%$ and better for after-patient contact $42.8 \%$. However lower for before patient contact $2.4 \%$, before a clean or aseptic procedure $3.6 \%$, and after contact with patient surroundings $3.3 \%[15]$. Also in Karaaslan, et al., (2014) study, the level of compliance relative to WHO five moments of hand hygiene was: overall compliance before patient contact was $43.2 \%$, before a clean/aseptic procedure was $8.5 \%$, after body fluid exposure was $18.1 \%$, after contact with patients was $68.1 \%$, and after contact with patient surroundings was $43.2 \%$.

\section{Limitation}

This study is not without limits, the study was unable to explore all factors known to be associated with hand hygiene compliance.

\section{CONCLUSION}

The study recorded very good hand hygiene compliance among the nurses. The factor that predicted non-compliance included: the ward of the department, the shift of the day, the occupational category of the nurse observed, and the kind of hand hygiene indicator.

\section{REFERENCES}

[1] Sarani, H., Balouchi, A., Masinaeinezhad, N., Ebrahimitabas, E. Knowledge, Attitude and Practice of Zabol University of Medical Sciences (2014). Glob J Health Sci. 2015; 8: doi:http://dx.doi.org/10.5539/gjhs.v8n3p193

[2] Trampuz, A., Widmer, A. Hand Hygiene: A frequently missed lifesaving opportunity during patient care. Mayo Clin Proc. 2004; 79: 109-16. doi:10.4065/79.1.109

[3] Jain, M., Dogra, V., Mishra, B., Thakur, A., Loomba, P. S. Infection control practicesamong doctors and nurses in a tertiary care hospital. Ann Trop Med Public Health 2012; 5: 29-33.

[4] Mathur, P. Hand hygiene: Back to the basics of infection control. Indian J Med Res. 2011; 134: 611-20. doi:10.4103/0971-5916.90985

[5] CDC. CDC Features. Centers for Disease Control and Prevention. 2017 https://www.cdc. gov/features/handhygiene/index.html

[6] WHO. WHO Guidelines on Hand Hygiene in Health Care: a Summary. Geneva: World Health Organisation 2009:https://www. who.int/gpsc/5may/tools/who_guidelineshandhygiene_summary.pdf

[7] Nakamura, R. K., Tompkins, E. Nosocomial Infection. Compendium 2012;https://www. researchgate.net/publication/223970186

[8] Labi, A.-K., Obeng-Nkrumah, N., Owusu, E., Bjerrum, S., Bediako-Bowan, A., SunkwaMills, G. et al. Hospital-acquired infections in Ghana. J. Hosp. Infect.2018; 1-34 doi:10. 1016/j.jhin.2018.04.019

[9] Labi, A.-K., Obeng-Nkrumah, N., Nuertey, B. D., Issahaku, S., Ndiaye, N. F., Baffoe, P., et al. Hand hygiene practices and perceptions among healthcare workers in Ghana: A WASH intervention study. J Infect Dev Ctries. 2019; 13: 1076-85. doi:10.3855/jidc. 11045

[10] Buerhaus, P. I., Auerbach, D. I., Staiger, D. O. Recent trends in the registered nurse labor market in the U.S.: short-run swings on top of long-term trends. Nurs Econ. 2007; 25: 59-66.

[11] American Association of Colleges of Nursing. Nursing Fact Sheet. American Association of Colleges of Nursing 2019; https://www. aacnnursing.org/News-Information/Fact-

Sheets/Nursing-Fact-Sheet\#: :text=Nurses $\% 20$ comprise \%20the\%20largest\%20component,the $\% 20$ average $\% 20$ for $\% 20$ all\%20occupations.

[12] Karaaslan, A., Kadayifci, E. K., Atıcı, S., Sili, U., Soysal, A., Çulha, G. et al. Compliance of Healthcare Workers with Hand Hygiene Practices in Neonatal and Pediatric Intensive Care Units: Overt Observation. Interdiscip Perspect Infect Dis. 2014; 1-5. doi:http://dx.doi. org/10.1155/2014/306478

[13] Amissah, I., Salia, S., Craymah, J. P. A Study to Assess Hand Hygiene Knowledge and 
Practices among Healthcare Workers in Teaching Hospital in Ghana. IJSR 2016; 5: doi:10.21275/ART2016631

[14] Engdaw, G. T., Gebrehiwot, M., Andualem, Z. Hand hygiene compliance and associated factors among health care providers in central Gonder zone public primary hospitals, Northwest Ethiopia. Engdaw et al. Antimicrob Resist Infect Control, 2019; 8: 1 - 7. doi:https:// doi.org/10.1186/s13756-019-0634-z

[15] Kolola, T., Gezahegn, T. A twenty-four-hour observational study of hand hygiene compliance among health care hospital,
Ethiopia. Antimicrob Resist Infect Control 2017; 1-5. doi:10.1186/s13756-017-0268-y

[16] Ghana Statistical Service. 2010 population and housing census district analytical report: Tamale Metropolis. Accra: Ghana Statistical Service 2014.www.statsghana.gov.gh/docfiles/ 2010_District_Report/.../Tamale\%20Metropolit an.pd...

[17] Alhassan, A. R., Kuugbee, E., \& Der, E. (2020, November 23). Surgical Healthcare Providers' Compliance to Hand Hygiene and Facemask Use: A Case of Tamale Teaching Hospital, Ghana. J PrevInfecContr, 6(4:51). doi:10. 36648/2471-9668.6.4.51.

Citation: Abdul Rauf Alhassan, Nurses Hand Hygiene Compliance: An Observational Studyin Tamale Teaching Hospital, Ghana. ARC Journal of Nursing and Healthcare. 2020; 6(2):28-34. DOI: doi.org/ 10.20431/2455-4324.0602005.

Copyright: () 2020 Authors. This is an open-access article distributed under the terms of the Creative Commons Attribution License, which permits unrestricted use, distribution, and reproduction in any medium, provided the original author and source are credited. 